Tohoku J. Exp. Med., 2004, 204, 257-266

\title{
Growth Hormone Cannot Enhance the Recovery of Dexamethasone-Induced Osteopenia after Withdrawal in Young Female Wistar Rats
}

\author{
Tien-Shang Huang, Rong-Sen Yang, Tsang-Wu Tsai ${ }^{2}$ and Shin-Hwa Liu ${ }^{1}$ \\ Departments of Internal Medicine, Orthopedics and ${ }^{1}$ Toxicology, ${ }^{2}$ Experimental \\ Animal Center, College of Medicine, National Taiwan University \& Hospital, \\ Taipei, Taiwan
}

Huang, T.-S., Yang, R.-S., Tsai, T.-W. and Liu, S.-H. Growth Hormone Cannot Enhance the Recovery of Dexamethasone-Induced Osteopenia after Withdrawal in Young Female Wistar Rats. Tohoku J. Exp. Med., 2004, 204 (4), 257-266 — Dexamethasone (DEX) suppresses the secretion of and responsiveness to growth hormone $(\mathrm{GH})$. Here we aimed to assess the therapeutic effects of GH on the DEX-induced osteopenia. Female Wistar rats were treated for 2 weeks with DEX (200 $\mu \mathrm{g} /$ day) or saline as a control. DEX significantly decreased body weight gain, bone mineral density (BMD), growth plate thickness, area ratio of trabecular bone, and serum osteocalcin levels. DEX also elongated the tibia primary spongiosa and caused many tiny lipid droplets in the tibia marrow. These results indicated that DEX induced osteopenia in rats. We then assessed the effects of GH on the recovery of osteopenia after withdrawal of DEX. DEX-treated rats were subsequently treated for 1 week with $\mathrm{GH}(0.1$ or $0.3 \mathrm{U} /$ day $)$ or saline, while saline-pretreated rats were treated for 1 week with saline as a control. GH ( 0.1 or $0.3 \mathrm{U} /$ day)-treated rats showed a catch-up growth in various bone measurements by one week after DEX withdrawal, though most of them remained subnormal. GH treatment did not enhance the recovery of DEX-induced osteopenia. Therefore a short-term exposure to DEX significantly impaired the bone metabolism, which started to recover soon after withdrawal of DEX. Unfortunately, immediate administration of GH after withdrawal of DEX did not enhance the recovery process. —— dexamethasone; osteopenia; growth hormone; bone mineral density; osteocalcin (C) 2004 Tohoku University Medical Press

Received May 31, 2004; revision accepted for publication September 28, 2004.

Address for reprints: Rong-Sen Yang, M.D., Professor of Department of Orthopedics, College of Medicine, National Taiwan University \& Hospital, No. 7, Chung-Shan South Road, Taipei, Taiwan.

e-mail: yang@ha.mc.ntu.edu.tw 
Glucocorticoids (GCs)-induced osteoporosis (GIO) has been shown to be associated with decreased secretion and function of sex steroids (hypogonadism) (Lukert and Raisz 1990; Reid 1997), growth hormone, insulin-like growth factor-I (IGF-I) (McCarthy et al. 1990; Bozzola et al. 1991; Miell et al. 1991; Rydziel and Canalis 1995; Ward et al. 1998), and serum osteocalcin (Prummel et al. 1991), as well as a suppressed activity and shorter active life span of osteoblasts (Dempster et al. 1983). Additionally, GIO may be related to a secondary hyperparathyroidism due to decreased gastrointestinal calcium absorption and increased urinary calcium excretion (Adler and Rosen 1994; Canalis 1996; Reid 1997). Thus GIO is associated with a suppressed bone formation and an accelerated bone resorption. Since GIO usually takes several years or longer to recover after withdrawal of GCs (Pocock et al. 1987; Lufkin et al. 1988; Aaron et al. 1989; Lukert and Raisz 1990; Adler and Rosen 1994; Gennari 1994; Hermus et al. 1994; Canalis 1996; Reid 1997), these patients may have a higher risk of osteoporosis-related fractures. Unfortunately, only few agents have been used to treat GIO with various therapeutic effects, such as bisphosphonates, hormone replacement therapy, and calcitonin (Montemurro et al. 1991; Lukert et al. 1992; Adachi 1997; Sambrook et al. 2003; Watts 2003).

Growth hormone $(\mathrm{GH})$ is important in the regulation of normal growth and development through enhancing the proliferation and function of chondrocytes (Nilsson et al. 1986; Rappaport et al. 1987; Trippel et al. 1989; Reinecke et al. 2000) and osteoblasts (Barnard et al. 1991; Kassem et al. 1993; Saggese et al. 1993), as well as enhancing bone formation (Brixen et al. 1993; Eriksen et al. 1993; Slootweg 1993; Vandeweghe et al. 1993; Inzucchi and Robbins 1994). Therefore, GH may be a potential candidate to ameliorate the detrimental effects in GIO, especially during the recovery period after withdrawal of GCs. In this study, we aimed to evaluate the possible therapeutic effects of GH on the recovery of GIO.

\section{Materials ANd Methods}

Animals

Thirty-six female Wistar rats, weighing from 140 to $160 \mathrm{~g}$, were obtained from the Animal Center of National Taiwan University. All the animals were kept under controlled conditions which included a $22 \pm 1^{\circ} \mathrm{C}$ environmental temperature and a 12:12 hours light-dark cycle. Animals were fed with Purina Laboratory Rodent Diet $\left(\mathrm{PMI}^{\circledR}\right.$ [St. Louis, MO, USA], $0.95 \%$ calcium) and distilled water ad libitum. Body weight of all the animals was measured weekly during the experimental periods. The procedures of animal experiment in this study were permitted by Laboratory Animal Center in National Taiwan University College of Medicine.

\section{Experimental design}

Animals were randomly assigned into six groups (6 rats for each group). To investigate the detrimental effects of dexamethasone (DEX) on the bone metabolism, rats were intraperitoneally (i.p.) injected for 2 weeks with DEX (200 $\mu$ g/day) (Merck Sharp Dohme \& Co., West Point, NJ, USA) in the morning or with saline as a control. These rats were sacrificed by decapitation 24 hours after last injection. The recombinant human GH has been demonstrated to have the effects on the rat skeletons (Andressen and Oxlund 2000; Feldman et al. 2004), and thus we assessed the therapeutic effects of recombinant human GH (rhGH, Pharmacia and Upjohn, Peapack, Denmark) on the recovery from DEX-induced osteopenia. The DEX-treated rats were subsequently treated for 1 more week with $\mathrm{GH}$ ( 0.1 or 0.3 U/day) or saline (DEX-withdrawal rats), while saline-pretreated rats were treated for 1 week with saline as a control. GH was given by i.p. injection in the afternoon. Rats were sacrificed by decapitation 18 hours after last injection of GH or saline.

\section{Bone turnover markers measurement}

The animal blood was collected after decapi- 
tation for measurements of bone turnover markers, including serum levels of C-terminal telopeptide of type I collagen (ICTP) as a bone resorption marker and osteocalcin as a bone formation marker. Serum ICTP was measured using rat-ICTP RIA kit (Orion Diagnostica, Espoo, Finland; interand intra-assay correlative variation less than $10 \%)$. The serum levels of osteocalcin were measured with a rat osteocalcin RIA kit (Biomedical Technologies Inc., Stoughton, MA, USA; interand intra- assay correlative variation less than $8 \%)$.

\section{Bone sample preparation}

After the animals were sacrificed, both femurs and tibiae were dissected immediately. The length of femur was measured with a precision caliper $( \pm 0.05 \mathrm{~mm})$. The wet weights of femur were measured before storage under $-20^{\circ} \mathrm{C}$. The proximal tibial metaphysis was resected and then fixed in $70 \%$ ethanol, decalcified in $0.5 \mathrm{~N} \mathrm{HCl}$, dehydrated in ascending series of ethanol and acetone, and embedded in paraffin. Longitudinal thin sections $(5 \mu \mathrm{m})$ of proximal tibia were cut and stained with Mayer's hematoxylin-eosin solution as previously described (Yang et al. 1993).

\section{Bone mineral density measurement}

Bone mineral density (BMD) of tibia and lumbar spine was measured with Norland XR-26 dual-energy X-ray absorptiometer (DXA, Fort Atkinson, WI, USA). A coefficient of variation of $0.7 \%$ was calculated from daily measurement of BMD on a lumbar phantom for more than 1 year. $B M D$ values were obtained through the original software of this densitometer.

\section{Histomorphometric analysis}

The histomorphometry study was performed with a semi-automated image-analyzing computer as previously described (Lab-Vision System Model LV-2 Image Analyzer, Pointek Computer Co., Ltd., Taipei, Taiwan) (Yang et al. 1993). The primary spongiosa and the secondary spongiosa extending from 1.0-3.0 $\mathrm{mm}$ distal to the epiphyse- al growth plate were analyzed. The measured parameters included the thickness of growth plate, thickness of cortical bone and the area ratio of total bone trabeculae in the secondary spongiosa. All data were presented as mean \pm S.E.

\section{Bone ash weight}

After thawed at room temperature for 1 hour, the fat of femurs was extracted with ethyl ether for 4 to 5 days. Then, the femurs were dried at $110^{\circ} \mathrm{C}$ overnight, ashed at $800^{\circ} \mathrm{C}$ for 4 hours, and then weighted (Demiralp et al. 2002).

\section{Statistical analysis}

Group data were analyzed by two-way analysis of variance (two-way ANOVA). $P$ value $(<0.05)$ was considered to be significant. Bonferroni $t$-test was performed for multiple comparison.

\section{Results}

\section{Body weight gain}

During the experimental period, all the animals did not show any diarrhea, vomiting, infection or local complications at the sites of injection. DEX treatment significantly suppressed the body weight gain, even after withdrawal and GH administration $(p<0.0001)$ (Table 1$)$. However, DEX-treated rats gained 66 gm after one-week withdrawal of DEX, whereas the rats treated with saline for 3 weeks gained $55 \mathrm{gm}$. Such a body weight gain after withdrawal of DEX showed a significant catch-up $(p<0.001)$. However, GH treatment $(0.1$ or $0.3 \mathrm{U} /$ day $)$ after withdrawal of DEX did not further enhance the body weight gain (Table 1).

\section{Bone mineral density}

DEX treatment for 2 weeks significantly decreased the bone mineral density (BMD) of lumbar spine (LS) $(0.109 \pm 0.007$ vs $0.125 \pm 0.005, p$ $<0.005)$ and tibia $(0.101 \pm 0.007$ vs $0.113 \pm 0.005$, $p<0.005$ ) (Table 1). After one-week withdrawal of DEX, rats showed a catch-up in LS BMD as compared with control $(3 \mathrm{w})$ rats $(0.126 \pm 0.009$ 
TABLE 1. Effects of dexamethasone (DEX) and growth hormone $(G H)$ on the body weight $(B W)$, bone mineral densities $(B M D)$ of lumbar spine $(L S)$ and the tibia $(T)$

\begin{tabular}{lcccc}
\hline \multicolumn{1}{c}{ Groups } & $\begin{array}{c}\text { Initial BW } \\
(\mathrm{g})\end{array}$ & $\begin{array}{c}\text { Final BW } \\
(\mathrm{g})\end{array}$ & $\begin{array}{c}\text { BMD (LS) } \\
\left(\mathrm{g} / \mathrm{cm}^{2}\right)\end{array}$ & $\begin{array}{c}\text { BMD (T) } \\
\left(\mathrm{g} / \mathrm{cm}^{2}\right)\end{array}$ \\
\hline DEX-treated (2w) & $150.3 \pm 7.6$ & $167.2 \pm 11.8$ & $0.109 \pm 0.007$ & $0.101 \pm 0.007$ \\
Control (2w) & $150.5 \pm 4.5$ & $256.8 \pm 16.5$ & $0.125 \pm 0.005$ & $0.113 \pm 0.005$ \\
\multicolumn{1}{c}{$p$} & $\mathrm{NS}$ & $<0.0001$ & $<0.005$ & $<0.005$ \\
& & & & \\
DEX-withdrawal & $154.5 \pm 7.0$ & $233.2 \pm 13.1^{\mathrm{a}}$ & $0.126 \pm 0.009$ & $0.125 \pm 0.007$ \\
GH (0.1 U/d)-treated & $150.2 \pm 5.0$ & $214.2 \pm 10.2^{\mathrm{a}}$ & $0.115 \pm 0.009^{\mathrm{a}, \mathrm{b}}$ & $0.109 \pm 0.003^{\mathrm{b}}$ \\
GH (0.3 U/d)-treated & $153.5 \pm 4.7$ & $212.3 \pm 11.1^{\mathrm{a}}$ & $0.117 \pm 0.005^{\mathrm{a}, \mathrm{b}}$ & $0.124 \pm 0.010$ \\
Control (3w) & $155.1 \pm 6.3$ & $311.4 \pm 12.2$ & $0.130 \pm 0.006$ & $0.116 \pm 0.012$ \\
\multicolumn{1}{c}{$p$} & $\mathrm{NS}$ & $<0.0001$ & $<0.0001$ & 0.001 \\
\hline
\end{tabular}

Each group, $n=6$; Data presented as mean \pm S.E.

NS, not significant.

${ }^{\mathrm{a}}$ vs Control $(3 \mathrm{w})$ rats: $p<0.05$.

${ }^{\mathrm{b}}$ vs DEX-withdrawal rats: $p<0.05$.

vs $0.130 \pm 0.006$, nonsignificant), whereas $\mathrm{GH}$ treatment ( 0.1 or $0.3 \mathrm{U} /$ day) after withdrawal of DEX showed a lower LS BMD (Table 1). The increment of tibial BMD in after one-week withdrawal of DEX was similar. Though GH (0.1 U/day) administration did not increase the tibia BMD, GH (0.3 U/day)-treatment ameliorated the tibia, but not lumbar spine, BMD (Table 1).

\section{Femur measurements}

Treatment with DEX for 2 weeks decreased the femur length and wet weight as compared to those treated with saline $(p<0.0001)$ (Table 2). DEX-treated rats still had a shorter femur length $(2.97 \pm 0.05 \mathrm{~cm}$ vs $3.18 \pm 0.12 \mathrm{~cm}, p<0.05)$ after one-week withdrawal of DEX, whereas they showed a significant catch-up of length $(0.12 \mathrm{~cm})$ than the rats treated with saline $(0.02 \mathrm{~cm}$ gain) $(p$ $<0.001)$. GH treatment ( 0.1 or $0.3 \mathrm{U} /$ day) after withdrawal of DEX did not further ameliorate the femur length (Table 2). GH (0.1 U/day)-treated rats even showed a significantly shorter length

TABLE 2. Effects of dexamethasone (DEX) and growth hormone $(G H)$ on various measurements of the femur

\begin{tabular}{lccc}
\hline \multicolumn{1}{c}{ Groups } & Length $(\mathrm{cm})$ & Wet weight $(\mathrm{mg})$ & Ash weight $(\mathrm{mg})$ \\
\hline DEX-treated (2w) & $2.85 \pm 0.07$ & $650.3 \pm 52.4$ & ND \\
Control (2w) & $3.16 \pm 0.06$ & $836.7 \pm 48.8$ & ND \\
\multicolumn{1}{c}{$p$} & $<0.0001$ & $<0.0001$ & \\
DEX-withdrawal & $2.97 \pm 0.05^{\mathrm{a}}$ & $650.2 \pm 54.8^{\mathrm{a}}$ & $627.5 \pm 51.4^{\mathrm{a}}$ \\
GH (0.1 U/d)-treated & $2.82 \pm 0.08^{\mathrm{a}, \mathrm{b}}$ & $648.9 \pm 53.4^{\mathrm{a}}$ & $557.5 \pm 55.1^{\mathrm{a}}$ \\
GH (0.3 U/d)-treated & $2.95 \pm 0.08^{\mathrm{a}}$ & $649.1 \pm 52.9^{\mathrm{a}}$ & $598.7 \pm 31.1^{\mathrm{a}}$ \\
Control (3w) & $3.18 \pm 0.12$ & $766.7 \pm 51.6$ & $722.0 \pm 18.6$ \\
\multicolumn{1}{c}{$p$} & $<0.0001$ & $<0.0001$ & $<0.0001$ \\
\hline
\end{tabular}

Each group, $n=6$; Data presented as mean \pm S.E.

$\mathrm{ND}$, no data.

${ }^{\mathrm{a}}$ vs Control (3w) rats: $p<0.05$.

${ }^{\mathrm{b}}$ vs DEX-withdrawal rats: $p<0.05$. 
than the rats treated with saline for 3 weeks. The wet weight and ash weight gain were not ameliorated by the $\mathrm{GH}$ administration, either.

\section{Bone histomorphometry}

The histological sections of tibiae of the control rats showed a normal growth plate (Fig. 1A) and well-developed bone trabeculae in both primary spongiosa and secondary spongiosa (Figs. $1 \mathrm{~A} 1$ and $1 \mathrm{~A} 2$ ). On the other hand, the administration of DEX for 2 weeks decreased the growth plate thickness (Fig. 1B1), elongated primary spongiosa and decreased the area ratio of bone trabeculae in the secondary spongiosa (Fig. 1B2) (Table 3). There were many fat droplets present among the bone trabeculae in the secondary spongiosa (Fig. 1B). The foci of new woven bone formation also decreased in the secondary spongiosa.

After one-week withdrawal of DEX, the rats showed an increase of thickness in growth plate, a significant thickening of primary spongiosa but a decrease in cortical thickness, whereas the area ratio of bone trabeculae returned to normal level as compared to rats treated with saline for 3 weeks (Table 3$)$. GH treatment ( 0.1 or 0.3 U/day) for 1 week ameliorated these aforementioned parameters significantly except for the area ratio of trabeculae in secondary spongiosa as compared to rats treated with saline for 3 weeks. However, GH treatment showed no further benefit in histo-

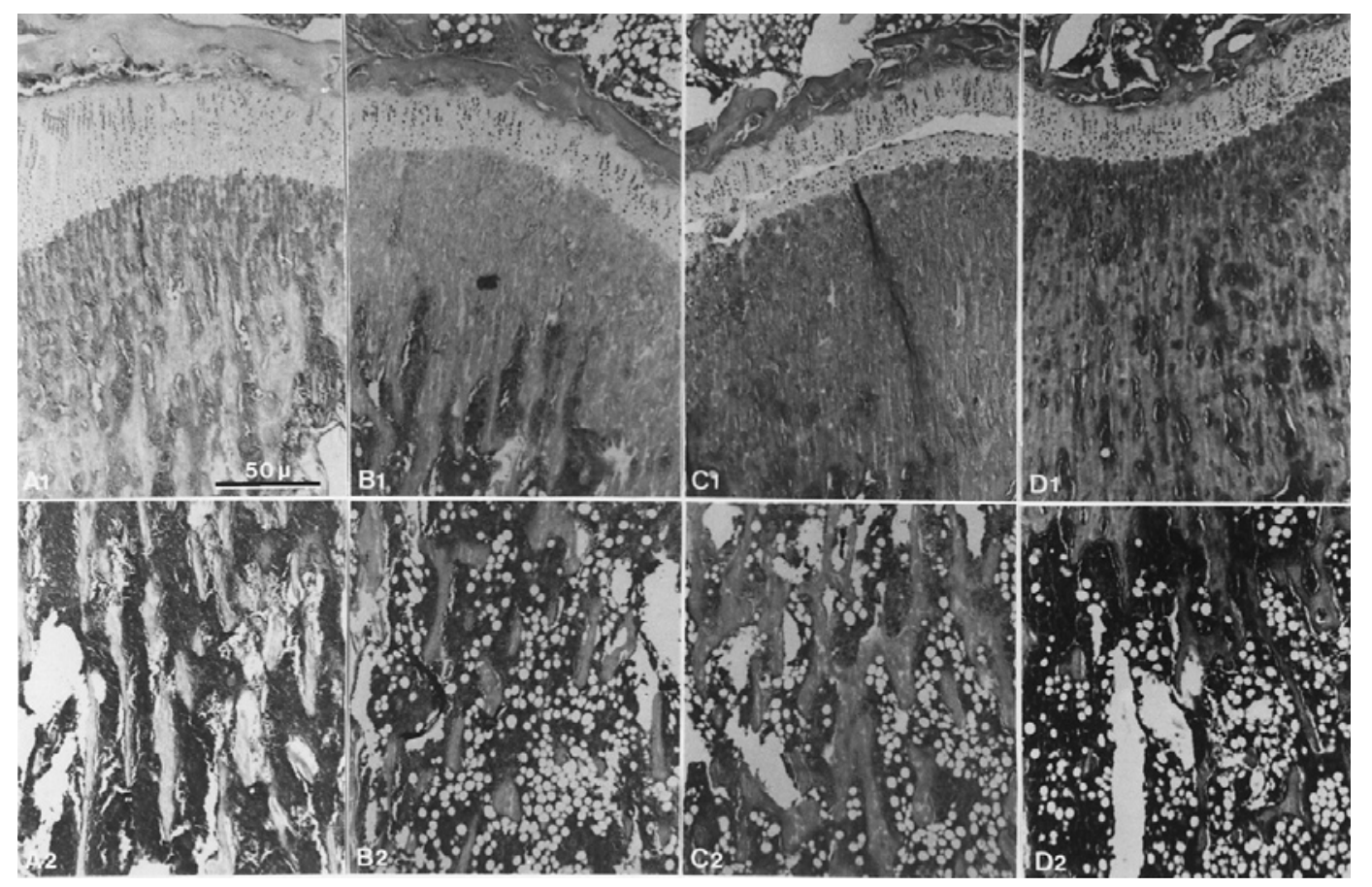

Fig. 1. Effects of systemic dexamethasone and growth hormone on the bone histomorphometry measurements in the rat tibia.

(A) Photomicrographs of decalcified tibia of rats receiving intraperitoneal saline injection demonstrated a normal growth plate, primary spongiosa and secondary spongiosa (A1 \& A2). (Bar length: $50 \mu)$.

(B) The intraperitoneal administration of dexamethasone $200 \mu \mathrm{g} / \mathrm{day}$ for 2 weeks caused a thinning growth plate, elongated primary spongiosa (B1), and decreased area ratio of bone trabeculae in the secondary spongiosa (B2). There were many tiny fat droplets among the bone trabeculae of the secondary spongiosa (B2).

(C) \& (D) Administration of growth hormone (0.1 U/day, C or $0.3 \mathrm{U} /$ day, D) ameliorated the dexamethasone-induced impairment of the trabecular microstructure. But the degree of improvement did not exceed those found in the rats treated with saline after withdrawal. 
TABLE 3. Effects of dexamethasone (DEX) and growth hormone $(G H)$ on various histomorphometric measurements of the tibia

\begin{tabular}{lcccc}
\hline \multicolumn{1}{c}{ Groups } & $\begin{array}{c}\text { Growth plate } \\
(\mathrm{mm})\end{array}$ & $\begin{array}{c}\text { Primary spongiosa } \\
(\mathrm{mm})\end{array}$ & $\begin{array}{c}\text { Cortical thickness } \\
(\mathrm{mm})\end{array}$ & $\begin{array}{c}\text { Area ratio of } \\
\text { trabeculae }(\%)\end{array}$ \\
\hline DEX-treated $(2 \mathrm{w})$ & $0.33 \pm 0.05$ & $1.35 \pm 0.21$ & $0.34 \pm 0.10$ & $24.31 \pm 5.30$ \\
Control (2w) & $0.51 \pm 0.03$ & $0.89 \pm 0.17$ & $0.37 \pm 0.04$ & $30.04 \pm 5.04$ \\
\multicolumn{1}{c}{$<$} & $<0.0001$ & $<0.005$ & $\mathrm{NS}$ & $\mathrm{NS}$ \\
& & & \\
DEX-withdrawal & $0.31 \pm 0.02$ & $1.21 \pm 0.29^{\mathrm{a}}$ & $0.30 \pm 0.04^{\mathrm{a}}$ & $25.64 \pm 6.49$ \\
GH (0.1 U/d)-treated & $0.33 \pm 0.04^{\mathrm{a}}$ & $1.54 \pm 0.26^{\mathrm{a}}$ & $0.32 \pm 0.10^{\mathrm{a}}$ & $28.08 \pm 5.15$ \\
GH (0.3 U/d)-treated & $0.34 \pm 0.02^{\mathrm{a}}$ & $1.39 \pm 0.30^{\mathrm{a}}$ & $0.35 \pm 0.10^{\mathrm{a}}$ & $28.05 \pm 4.32$ \\
Control (3w) & $0.27 \pm 0.04$ & $0.68 \pm 0.05$ & $0.44 \pm 0.06$ & $26.23 \pm 2.86$ \\
\multicolumn{1}{c}{$p$} & $<0.005$ & $<0.0001$ & $<0.005$ & $\mathrm{NS}$ \\
\hline
\end{tabular}

Each group, $n=6$; Data presented as mean \pm s.E.

NS, not significant.

${ }^{\mathrm{a}}$ vs Control ( $\left.3 \mathrm{w}\right)$ rats: $p<0.05$.

TABLE 4. Effects of (DEX) and growth hormone (GH) on serum osteocalcin and C-terminal telopeptide of type I collagen (ICTP) levels

\begin{tabular}{ccc}
\hline \multicolumn{1}{c}{ Groups } & Osteocalcin $(\mathrm{ng} / \mathrm{ml})$ & ICTP $(\mu \mathrm{g} / \mathrm{l})$ \\
\hline DEX-treated $(2 \mathrm{w})$ & $26.0 \pm 7.6$ & $15.0 \pm 4.9$ \\
Control (2w) & $54.5 \pm 13.9$ & $15.2 \pm 1.1$ \\
\multicolumn{1}{c}{$p$} & $<0.005$ & $\mathrm{NS}$ \\
DEX-withdrawal & $24.9 \pm 3.6$ & $14.8 \pm 3.1^{\mathrm{a}}$ \\
GH $(0.1 \mathrm{U} / \mathrm{d})$-treated & $36.2 \pm 7.0^{\mathrm{a}}$ & $15.1 \pm 3.7^{\mathrm{a}}$ \\
GH $(0.3 \mathrm{U} / \mathrm{d})$-treated & $26.7 \pm 4.9$ & $14.3 \pm 1.6^{\mathrm{a}}$ \\
Control (3w) & $28.6 \pm 3.5$ & $10.2 \pm 2.7$ \\
\multicolumn{1}{c}{$p$} & $<0.0001$ & $<0.005$ \\
\hline
\end{tabular}

Each group, $n=6$; Data presented as mean \pm S.E.

NS, not significant.

${ }^{a}$ vs Control (3w) rats: $p<0.05$.

morphometric parameters as compared with those rats treated with saline after withdrawal of DEX (Table 3) (Fig. 1C1-1D2).

\section{Bone turnover marker assay}

DEX treatment for 2 weeks significantly reduced serum osteocalcin levels $(26.0 \pm 7.6$ vs 54.5 $\pm 13.9, p<0.005)$, whereas the serum ICTP levels were not different (Table 4). Treatment of the saline-pretreated rats with saline for one week showed a decrease of both serum osteocalcin and ITCP levels. As compared to the rats treated with saline for 3 weeks, GH (0.1 U/day)-treated rats showed a significant increase in serum osteocalcin and ITCP levels. On the other hand, treatment with GH (0.3 U/day) showed a significant increase in serum ITCP level, but not osteocalcin level (Table 4). No enhanced effects of GH treatment on the improvement of biochemical bone markers were detected as compared with the rats treated with saline after DEX withdrawal.

\section{Discussion}

In this study, young female Wistar rats re- 
ceiving intraperitoneal injection with DEX showed a slow body weight gain, shorter femur length, lighter femur weight, accompanied by a severe osteopenia proven by histomorphometry, BMD and serum osteocalcin assessments. The histomorphometric measurements were improved soon at 1 week after DEX withdrawal, although some parameters remained subnormal. However, the short-term administration of GH immediately (one week) after withdrawal of DEX did not effectively enhance the catch-up process.

Cushing's syndrome and a long-term administration of GCs induce a marked osteoporosis (Adler and Rosen 1994; Canalis 1996; Reid 1997). The possible mechanisms of GIO include increased bone resorption and reduced bone formation, such as thinning or perforation of trabeculae accompanied by markedly reduced trabecular volume (Aaron et al. 1989; Adler and Rosen 1994; Canalis 1996; Chappard et al. 1996; Reid 1997). Our histomorphologic studies confirmed the detrimental effects of DEX administration for 2 weeks, including decreased growth plate thickness by $35 \%$, increased primary spongiosa thickness by $52 \%$, and reduced area ratio of bone trabeculae in the secondary spongiosa by $19 \%$, as well as accumulation of many lipid droplets among the slender bone trabeculae in the tibial metaphysis. These conditions were confirmed by the marked decrease of BMD in the tibiae.

The suppressed serum osteocalcin level after the administration of corticosteroid was dose-dependent and reversible after withdrawal (Peretz et al. 1989). This study showed that treatment with DEX lowered the serum osteocalcin levels whereas the serum ICTP concentrations were not different from the control. It implied that the DEXinduced osteopenia and growth impairment may be related to a suppression of the osteoblasts. Therefore the withdrawal of DEX eliminated its inhibition on osteoblasts rather than its accelerated effect on bone resorption. Thus the catch-up growth in the early phase of withdrawal may show different patterns. The definite mechanism of catch-up growth after DEX withdrawal needs further investigation.

We showed that GCs inhibited the growth plate most markedly in the rapidly growing rats. Bozzola et al. (1991) demonstrated that shortterm high-dose prednisone treatment markedly suppressed GH and insulin-like growth factor levels that did not increase after withdrawal. It may partially explain the smaller femur length gain after DEX withdrawal. In addition, Leong et al. (1996) showed that GCs-induced osteopenia might not completely recover in an identical adolescent twin study. It implied an irreversible effect in the bone growth stage, i.e., the stage of rapid bone mass accumulation. Our results are relevant to the adolescents because the rats (12 week-old) in this study were in their rapid growing stage since rats continue to grow until age of 6 months. Although we have shown indeed a catch-up growth after withdrawal of DEX in present study, the recovery of bone growth after the withdrawal of DEX remained subnormal. Thus, decreasing exposure to GCs in the adolescent stage is very important to prevent the GCsinduced osteopenia.

The GCs-induced osteopenia has been proven related to the suppressed secretion of GH (Bozzola et al. 1991; Miell et al. 1991). Our previous study showed that the hypothalamus-pituitary-adrenal axis of DEX-treated rats recovered in about 2 weeks after withdrawal (Huang 1994). GH treatment on the GCs-induced osteopenia may increase bone formation and bone mass or density, with a wide range of therapeutic dose $(0.1$ U/day to $0.5 \mathrm{U} /$ day or more) and duration (1 week to 3 months) (Brixen et al. 1993; Eriksen et al. 1993; Slootweg 1993; Vandeweghe et al. 1993; Inzucchi and Robbins 1994; Ørtoft et al. 1999). Several studies have shown that GH improved the body composition, bone metabolism, and linear growth in the GCs-dependent children (Mauras 2001, 2002). Therefore GH has been expected to prevent, treat, or even facilitate the recovery of the GCs-induced osteopenia. These protective effects shown in the previous studies about combined GH therapy with GCs treatment might be 
due to a competition between GH and GCs, which were different from our GCs withdrawal status. In the present study, there was an enhanced bone turnover and increased bone density after DEXwithdrawal. However, there was no enhanced effect of GH therapy on the catch-up of femur weight, length as well as body weight.

The contradictory results of a significantly elevated serum osteocalcin level accompanied by a shorter femur length were observed in the rats treated with $\mathrm{GH}(0.1 \mathrm{U} /$ day, but not $0.3 \mathrm{U} /$ day $)$ after withdrawal of DEX. It may imply that there was a different recovery response to GH therapy during the withdrawal, either a slower initial response followed by a faster later response, or vice versa. GH may show a different sequential effect on the growth plate and osteoblasts. A higher serum osteocalcin level after early additional GH treatment may indicate an earlier starting to catch up the bone formation, rather than facilitating the femur length gain. The slow gain of femur length in the $\mathrm{GH}(0.1 \mathrm{U} /$ day $)$-treated rats may also be related to the initial smaller size as well as a slower body weight gain, i.e., a slow growth catch-up after withdrawal. Additionally, the catch-up phenomenon occurred soon after DEX withdrawal, it is possible that additional GH treatment did not enhance the optimal catch-up status of rats. Further studies are needed to elucidate the definite mechanisms.

\section{Conclusion}

This study showed a suppressed bone formation and significant osteopenia in the DEX-treated rats. The condition recovered soon but incompletely in the early stage of DEX withdrawal. A short-term additional GH therapy cannot enhance the recovery in immediate withdrawal stage. Thus, lowering exposure to GCs is important in the prevention and treatment of GCs-induced osteoporosis. Further studies are underway to assess the effects of long-term GH administration on GCs-induced osteoporosis.

\section{Acknowledgements}

This study is supported by a grant from National Science Council, NSC 86-2314-B-002-230. We also appreciated the great help from Dr. Tsang-Hai Huang, Ph.D., for his review of this manuscript.

\section{References}

Aaron, J.E., Francis, R.M., Peacock, M. \& Makins, N.B. (1989) Contrasting microanatomy of idiopathic and corticosteroid-induced osteoporosis. Clin. Orthop., 243, 294-305.

Adachi, J.D. (1997) Intermittent etidronate therapy to prevent corticosteroid-induced osteoporosis. New Engl. J. Med., 337, 382-387.

Adler, R.A. \& Rosen, C.J. (1994) Glucocorticoids and osteoporosis. Endocrinol. Metab. Clin. North Am., 23, 641-654.

Andreassen, T.T. \& Oxlund, H. (2000) The influence of combined parathyroid hormone and growth hormone treatment on cortical bone in aged ovariectomized rats. J. Bone Miner. Res., 15, 2266-2275.

Barnard, R., Ng, K.W., Martin, T.J. \& Waters, M.J. (1991) Growth hormone (GH) receptors in clonal osteoblasts-like cells mediate a mitogenic response to GH. Endocrinology, 128, 1459-1464.

Bozzola, M., Locatelli, F., Gambarana, D., Moretta, A., Valtorta, A., Giorgiani, G., Cisternino, M. \& Severi, F. (1991) Effect of corticoid therapy on growth hormone secretion. Horm. Res., 36, 183-186.

Brixen, K., Kassem, M., Eriksen, E.F., Nielsen, H.K., Flyvbjerg, A. \& Mosekilde, L. (1993) Growth hormone $(\mathrm{GH})$ and adult bone remodeling: the potential use of GH in treatment of osteoporosis. J. Ped. Endocrinol., 16, 65-71.

Canalis, E. (1996) Mechanisms of glucocorticoid action in bone: implications to glucocorticoid-induced osteoporosis. J. Clin. Endocrinol. Metab., 81, 3441-3447.

Chappard, D., Legrand, E., Basle, M.F., Fromont, P., Racineux, J.L., Rebel, A. \& Audran, M. (1996) Altered trabecular architecture induced by corticosteroids: a bone histomorphometric study. $J$. Bone Miner. Res., 11, 676-685.

Demiralp, B., Chen, H.L., Koh, A.J., Keller, E.T. \& McCauley, L.K. (2002) Anabolic actions of parathyroid hormone during bone growth are dependent on c-fos. Endocrinology, 143, 4038-4047. 
Dempster, D.W., Arlot, M.A. \& Meunier, P.J. (1983) Mean wall thickness and formation periods of trabeculae bone packets in corticosteroid-induced osteoporosis. Calcif. Tissue Int., 35, 410-417.

Eriksen, E.F., Kasse, M. \& Brixen, K. (1993) Growth hormone and insulin-like growth factor as anabolic therapies for osteoporosis. Horm. Res., 40, 95-98.

Feldman, S., Cointry, G.R., Leite Duarte, M.E., Sarrio, L., Ferretti, J.L. \& Capozza, R.F. (2004) Effects of hypophysectomy and recombinant human growth hormone on material and geometric properties and the pre- and post-yield behavior of femurs in young rats. Bone, 34, 203-215.

Gennari, C. (1994) Glucocorticoid induced osteoporosis. Clin. Endocrinol., 41, 273-274.

Hermus, A.R., Huysmans, D.A., Smals, A.G., Corstens, F.H. \& Kloppenborg, P.W. (1994) Remarkable improvement of osteopenia after cure of Cushing's syndrome. Horm. Metab. Res., 26, 209-210.

Huang, T.S. (1994) Adrenocorticotropin secretagogues facilitate recovery of the hypothalamuspituitary adrenal axis suppressed by prolonged treatment with dexamethasone. Metabolism, 43, 544-548.

Inzucchi, S.E. \& Robbins, R.J. (1994) Effects of growth hormone on human bone biology. $J$. Clin. Endocrinol. Metab., 79, 691-694.

Kassem, M., Blum, W., Ristelli, J., Mosekilde, L. \& Eriksen, E.F. (1993) Growth hormone stimulates proliferation and differentiation of normal human osteoblasts-like cells in vitro. Calcif. Tissue Int., 52, 222-226.

Leong, G.M., Mercado-Asis, L.B., Reynolds, J.C., Hill, S.C., Oldfield, E.H. \& Chrousos, G.P. (1996) The effect of Cushing's disease on bone mineral density, body composition, growth and puberty: a report of an identical adolescent twin pair. J. Clin. Endocrinol. Metab., 81, 1905-1911.

Lufkin, E.G., Wahner, H.W. \& Bergstralh, E.J. (1988) Reversibility of steroid-induced osteoporosis. Am. J. Med., 85, 887-888.

Lukert, B.P., Johnson, B.E. \& Robinson, R.G. (1992) Estrogen and progesterone replacement therapy reduces glucocorticoid-induced osteoporosis. $J$. Bone Miner. Res., 7, 1063-1069.

Lukert, B.P. \& Raisz, L.G. (1990) Glucocorticoid-induced osteoporosis: Pathogenesis and management. Ann. Intern. Med., 112, 352-364.
Mauras, N. (2001) Growth hormone therapy in the glucocorticosteroid-dependent child: metabolic and linear growth effects. Horm. Res., 56, Suppl. 1, 13-18.

Mauras, N., George, D., Evans, J., Milov, D., Abrams, S., Rini, A., Welch, S. \& Haymond, M.W. (2002) Growth hormone has anabolic effects in glucocorticosteroid-dependent children with inflammatory bowel disease: a pilot study. Metabolism, 51, 127-135.

McCarthy, T.L., Centrella, M. \& Canalis, E. (1990) Cortisol inhibits the synthesis of insulin-like growth factor-1 in skeletal cells. Endocrinology, 126, 1569-1575.

Miell, J.P., Corder, R., Pralong, F.P. \& Gaillard, R.C. (1991) Effects of dexamethasone on growth hormone $(\mathrm{GH})$ releasing hormone, arginineand dopaminergic stimulated GH secretion and total plasma insulin-like growth factor- 1 concentration in normal male volunteers. J. Clin. Endocrinol. Metab., 72, 675-681.

Montemurro, L., Schiraldi, G., Fraioli, P., Tosi, G., Riboldl, Q. \& Rizzato, G. (1991) Prevention of corticosteroid-induced osteoporosis with salmon calcitonin in sarcoid patients. Calcif. Tissue Int., 49, 71-76.

Nilsson, A., Isgaard, J., Lindahl, A., Dahlstrom, A., Skottner, A. \& Isaksson, O.G. (1986) Regulation by growth hormone of number of chondrocytes containing IGF-I in rat growth plate. Science, 233, 571-574.

Ørtoft, G., Andreassen, T.T. \& Oxlund, H. (1999) Growth hormone increases cortical and cancellous bone mass in young growing rats with glucocorticoid-induced osteopenia. J. Bone Miner. Res., 14, 710-721.

Peretz, A., Praet, J.P., Bosson, D., Rozenberg, S. \& Bourdoux, P. (1989) Serum osteocalcin in the assessment of corticosteroid induced osteoporosis. Effect of long and short term corticosteroid treatment. J. Rheumatol., 16, 363-367.

Pocock, N.A., Eisman, J.A., Dunstan, C.R., Evans, R.A., Thomas, D.H. \& Laila, H.N. (1987) Recovery from steroid-induced osteoporosis. Ann. Intern. Med., 107, 319-323.

Prummel, M.F., Wiersinga, W.M., Lips, P., Sanders, G.T.B. \& Sauerwien, H.P. (1991) The course of biochemical parameters of bone turnover during treatment with corticosteroids. J. Clin. Endocrinol. Metab., 72, 382-386.

Rappaport, E.B., Snoy, P., Habig, W.H. \& Bright, R.W. (1987) Effects of exogenous growth hormone 
on growth plate cartilage in rats. Am. J. Dis.

Child, 141, 497-501.

Reid, I.R. (1997) Glococorticoid osteoporosis: Mechanisms and management. Eur. J. Endocrinol., 137, 209-217.

Reinecke, M., Schmid, A.C., Heyberger-Meyer, B., Hunziker, E.B. \& Zapf, J. (2000) Effect of growth hormone and insulin-like growth factor I (IGF-I) on the expression of IGF-I messenger ribonucleic acid and peptide in rat tibial growth plate and articular chondrocytes in vivo. Endocrinology, 141, 2847-2853.

Rydziel, S. \& Canalis, E. (1995) Cortisol represses insulin-like growth factor-1 receptor transcription in skeletal cell cultures. Endocrinology, 136, 4254-4260.

Saggese, G., Federico, G. \& Cinquanta, L. (1993) In vitro effects of growth hormone and other hormones on chondrocytes and osteoblasts-like cells. Acta Paediatr. Suppl., 391, 54-59.

Sambrook, P.N., Kotowicz, M., Nash, P., Styles, C.B., Naganathan, V., Henderson-Briffa, K.N., Eisman, J.A., \& Nicholson, G.C. (2003) Prevention and treatment of glucocorticoid-induced osteoporosis: a comparison of calcitriol, vitamin D plus calcium, and alendronate plus calcium.
J. Bone Miner. Res., 18, 919-924.

Slootweg, M.C. (1993) Growth Hormone and bone. Horm. Metab. Res., 25, 335-343.

Trippel, S.B., Corvol, M.T., Dumontier, M.F., Rappaport, R., Hung, H.H. \& Mankin, H.J. (1989) Effect of somatomedin-C/insulin-like growth factor I and growth hormone on cultured growth plate and articular chondrocytes. Pediatr. Res., 25, 76-82.

Vandeweghe, M., Taelman, P. \& Kaufman, J.M. (1993) Short- and long-term effects of growth hormone treatment on bone turnover and bone mineral content in adult growth hormone-deficient males. Clin. Endocrinol., 39, 409-415.

Ward, W.E., Donovan, S.M. \& Atkinson, S.A. (1998) Dexamethasone-induced abnormalities in growth and bone metabolism in piglets are partially attenuated by growth hormone with no synergistic effect of insulin-like growth factor-I. Pediatr. Res., 44, 215-221.

Watts, N.B. (2003) Bisphosphonates treatment of osteoporosis. Clin. Geriatr. Med., 19, 395-414.

Yang, R.S., Liu, T.K. \& Lin-Shiau, S.Y. (1993) Increased bone growth by local prostaglandin E2 in rats. Calcif. Tissue Int., 52, 57-61. 